\title{
Delamination Analysis of Composite Sandwich Plate of Cork Agglomerate/Glass Fiber- Polyester: An Experimental Investigation
}

\author{
Hocine Djemai ${ }^{1}$, Adnane Labed $^{2 *}$, Mabrouk Hecini $^{2}$, Tarek Djoudi ${ }^{2}$ \\ ${ }^{1}$ Laboratory of Energy Engineering and Materials (LGEM), University of Biskra, Post box. 145 R.P. 07000, Biskra, Algeria \\ ${ }^{2}$ Laboratory of Mechanical Engineering (LGM), University of Biskra, Post box. 145 R.P. 07000, Biskra, Algeria
}

Corresponding Author Email: a.labed@univ-biskra.dz

https://doi.org/10.18280/rcma.310402

Received: 2 June 2021

Accepted: 4 August 2021

\section{Keywords:}

glass-polyester, cork agglomerate, sandwich, delamination, energy release rate, double cantilever beams

\begin{abstract}
This paper presents an experimental investigation of damage in sandwich structures. These sandwich panels are result of the combination of glass-polyester as skins and cork agglomerate as core. For this purpose, delamination test (mode I) is carried on double cantilever beams (DCB) in sandwich beams. The initiation crack is characterized by toughness obtained from the determination of energy release rate (GIC) by modified beam theory method. The skins of these sandwiches are considered as orthotropic materials while the core as isotropic transverse material. The results show that, the energy release rate at the initiation of the crack of (DCB) specimens remains almost constant despite the variation of the initial crack, a good adhesion (skins - core) is also noticed.
\end{abstract}

\section{INTRODUCTION}

The composite materials have gained great importance in the industrial fields. The sandwich structure is among the most used composite types. They are generally composed of two thin tough face sheets (skins) contain between them a lightweight core. The core is relatively flexible and weak while the skins are rigid, but they produce a strong and lightweight structure when combined in a sandwich panel [1, 2].

Different industrial sectors have turned to the use of sandwich structures, such us automobile and aerospace, because of their weight penalties, their flexural inertia and great absorption energy potential. Among laminates materials used resin (thermoplastic or thermosetting) reinforced by glass fibers or carbon fibers [3]. Many kinds of core materials are used; cork agglomerate, honeycomb, balsa, foam and petiole (date palm).

The sandwich material behavior is determined by using compression tests under crushing loads and the measurements of the ductile fracture limits $[3,4]$.

It is important to understand the properties of shear strength of sandwich core subjected to flexural loading. Therefore, flexural and shear rigidities of sandwich beams are often studied by using three-point bending tests $[5,6]$.

In previous studies, we conducted an experimental investigation for the improvement of solar flat plate collectors (FPCs) materials and efficiencies. We studied the effect of the use of four different sandwich panels in the rear insulation; two materials as skins (Glass-Polyster and Plywood) and two as cores (Polystyrene and cork agglomerate). These four sandwich panels were tested for three point-bending tests. We showed that, although the sandwich composed of Plywood as skins and Cork-agglomerate as core shows a slight thermal improvement, the use of the sandwich material composed of
Glass-Polystere in the skins and Cork agglomerate in the core can guarantees a good insulation and noticeable improvement in mechanical proprieties in comparison with other tested materials. For this reason, this sandwich material was selected as the most suitable material for this kind of application, and we added in this study another characterization test which is delamination.

It is worth noting here that, the components of the studied FPC model are; the absorber plate, the cover and the sandwich panels (Skins sheet/Insulator core) used as rear insulation (Figure 1). This rear insulation is solicited to several constraints, such as the weight of collectors and wind constraints. For this reason, three point bending and delamination tests are the most important proof in the damage study of the sandwich panels $[7,8]$.

In this study, DCB test is conducted using sandwich structures (cork agglomerate in the core and glass fiberpolyester in the skins) to investigate delamination characterization under mode-I (toughness $\mathrm{G}_{\mathrm{IC}}$ ) by modified beam theory method.

These tested sandwiches samples are made of cork agglomerate as core, sandwiched between glass fiberpolyester (laminate of four 04 layers) as skins. The experimental study consisted of elaborate different types of sandwiche samples to determine their break in mode I.

Delamination is a damage mode of sandwich structures, which can be particularly detrimental for structural behavior. Face/core separation and core cracking are failure modes in sandwich materials based by cork agglomerate in the core. Double cantilever beam (DCB) specimens are used for the determination of the fracture toughness of face/core sandwich specimens Compliance equation is used to calculate the energy release rate for double cantilever beam specimen [9-12].

These studied materials can be used as an insulating material, especially in solar air flat plate collectors and drying 
chambers. For this reason, this study will be followed by a second paper on the thermal characterization of different studied materials.

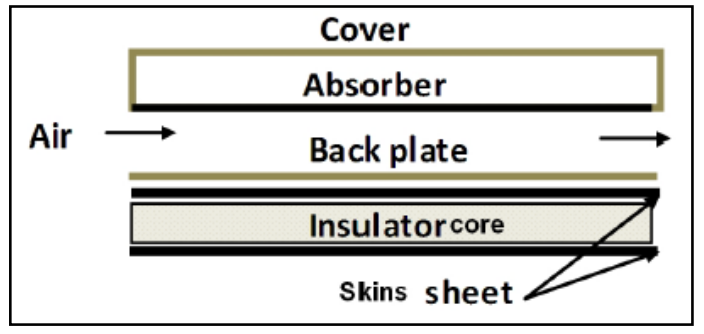

Figure 1. Schematic view of Flat Plat Collector model [7, 13]

\section{MODIFIED BEAM THEORY (MBT)}

The specimen presented in Figure 2 is a double cantilever beams (DCB). This specimen is more rigid in flexure under lower arm than upper arm. We can also say that, at large opening displacements there is a slight rotation of the specimen, but the actual specimens test indicate that this slight is small in such a rotation. The faces have thicknesses $\mathrm{h}_{\mathrm{f}}$, while the core thickness is $h_{c}[14]$.

The face laminates are considered as effective orthotropic materials because the fibers in the skins are thins, there direction is random in three directions. The core is composed of agglomerated cork grains of medium density and sized between 2 and $3 \mathrm{~mm}$, compensated in one direction and assembled with polyurethane resin, for that it is considered transverse isotropic material because the elastic properties exhibit symmetry of revolution around this direction.

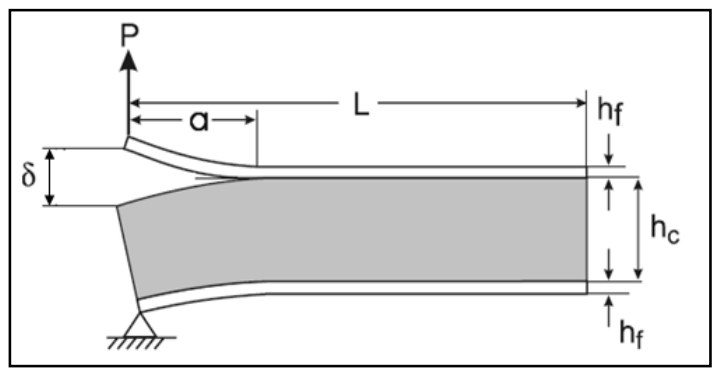

Figure 2. Sandwich DCB specimens [14]

The criterion of the crack energy increase and the stored elastic strain energy released when the driving force of crack increase. This energy could be as high as the energy required to originate new surfaces. The toughness is defined in this work by energy release rate. We can determine this latter in mode I using Irwin-Kies equation [14, 15]:

$$
G_{I C}=\frac{P^{2}}{2 b} \frac{d C}{d a}
$$

with: $P$ is the applied load, b: the specimen width, $\boldsymbol{a}$ : the crack length and $\mathrm{C}$ : the compliance, it's defined by:

$$
C=\frac{\delta}{P}
$$

where, $\delta$ is the crack's opening displacement.
The difficulty in applying the formula (1) lies in determining the ratio $(\mathrm{dC} / \mathrm{da})$, several methods are used to determine this ratio. To calculate of release energy strain rate $\left(\mathrm{G}_{\mathrm{IC}}\right)$ in this paper, we used modified beam theory (MBT).

The graph $C^{1 / 3}=f(a)$ is theoretically a straight line (Figure 3):

$$
C^{1 / 3}=m(a+|\Delta|)
$$

These parameters $m$ and $\Delta$ are obtained from the compliance at the initiation crack of several specimens differentiated by the size of the crack between the upper skin and the core.

Where, $m$ is the slope of the line $\mathrm{C}=\mathrm{f}(\mathrm{a})$ and $|\Delta|$ is the magnitude of the intercept of $\mathrm{C}=\mathrm{f}(\mathrm{a})$ with the (a)-axis. These parameters become intrinsic to the material.

To determine the energy release rate, Eqns. (1) and (3) are combined to yield.

$$
G_{I C}=\frac{3 P^{2} C}{2 b(a+|\Delta|)}
$$

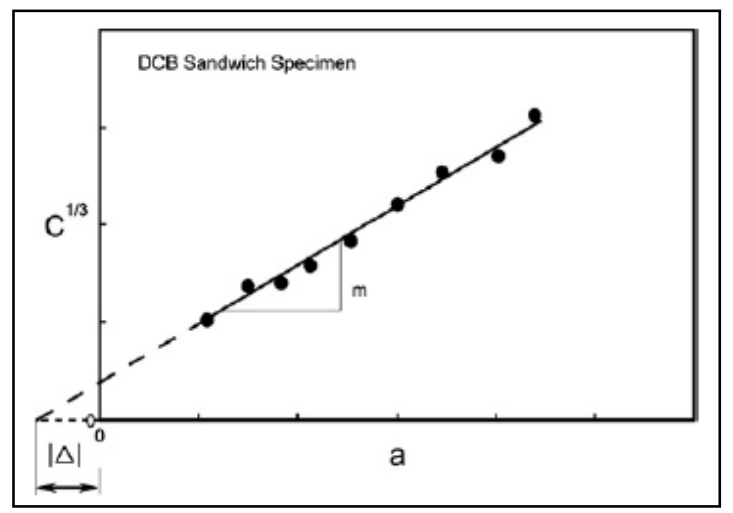

Figure 3. Schematic illustration of compliance calibration fit according to modified beam theory (MBT) approach [14]

\section{EXPERIMENTAL SETUP}

For the experimental work, the sandwiches used are made of cork agglomerate in the core between glass fiber-polyester (laminate of 04 layers) in the skins.

The dimensions and geometry of DCB specimen are illustrated graphically in Figure 4.

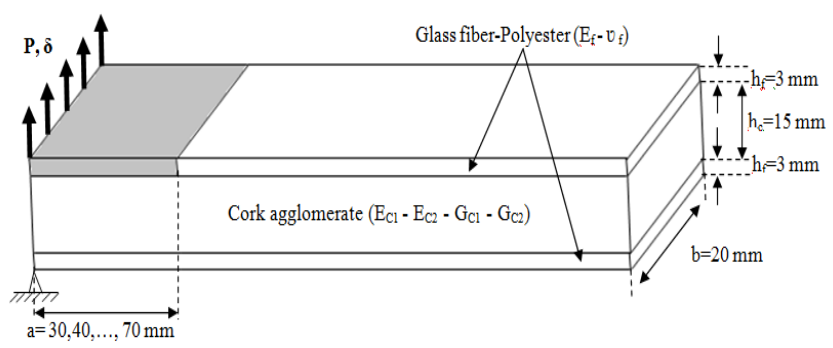

Figure 4. Geometry and dimensions of the DCB specimen

DCB specimens were fabricated at the department of Mechanical Engineering of Biskra University (Algeria). The sandwich panel was fabricated with adhesive bonding of the two skins (glass fiber-polyester) to the core (cork agglomerate).

The skins are composed of unsaturated polyester resin 
NORSODYNE S-2010-V and of random glass fiber. This composite is prepared at FIPEXPLAST located in Chlef (Algeria) by contact molding. It contains four layers at $33.33 \%$ fiber rate.

Natural cork was harvested from Jijel forests (Algeria) and was treated to the cork agglomerates at the industrial company "Taleza cork" based in Skikda, Algeria. The granules of the natural cork were assembled with polyurethane resin to prepare the cork agglomerates. Its density is $280 \mathrm{~kg} / \mathrm{m}^{3}$ and a thermal conductivity $(\lambda)$ is $0.0375 \mathrm{~W} / \mathrm{m}^{2} \quad \mathrm{~K}^{-1}$ [16], the mechanical characteristics of the skins and the core are presented in Table 1 and Table 2.

These DCB specimens were differentiated by the size of the initial crack. This latter is obtained by placing during the elaboration, an aluminum film between the core and the upper skin. The DCB specimens have different initial crack lengths $(\mathrm{a}=30,40,50,60$ and $70 \mathrm{~mm})$. See Figure 5.

Table 1. Mechanical characteristics of the skins

\begin{tabular}{cc}
\hline & Glass fiber-polyester \\
\hline $\mathbf{E}_{\mathbf{f}}(\mathbf{G p a})$ & 7.9022 \\
\hline vf $_{\mathrm{f}}$ & 0.3675 \\
\hline Panel thickness $(\mathbf{m m})$ & 3 \\
\hline Fiber mass fraction $(\%)$ & 33.33 \\
\hline
\end{tabular}

Table 2. Mechanical characteristics of the core [17]

\begin{tabular}{cc}
\hline Specimen & Cork agglomerate \\
\hline $\mathbf{E}_{\mathbf{C} 1}(\mathbf{G p a})$ & 20 \\
\hline $\mathbf{E}_{\mathbf{C} 3}(\mathbf{G p a})$ & 20 \\
\hline $\mathbf{E}_{\mathbf{C} 2}(\mathbf{G p a})$ & 5 \\
\hline $\mathbf{G}_{\mathbf{C} 1}(\mathbf{G p a})$ & 2.5 \\
\hline $\mathbf{G}_{\mathbf{C} 3}(\mathbf{G p a})$ & 2.5 \\
\hline $\mathbf{G}_{\mathbf{C} 2}(\mathbf{G p a})$ & 4.3 \\
\hline$v$ & 0.05 \\
\hline
\end{tabular}

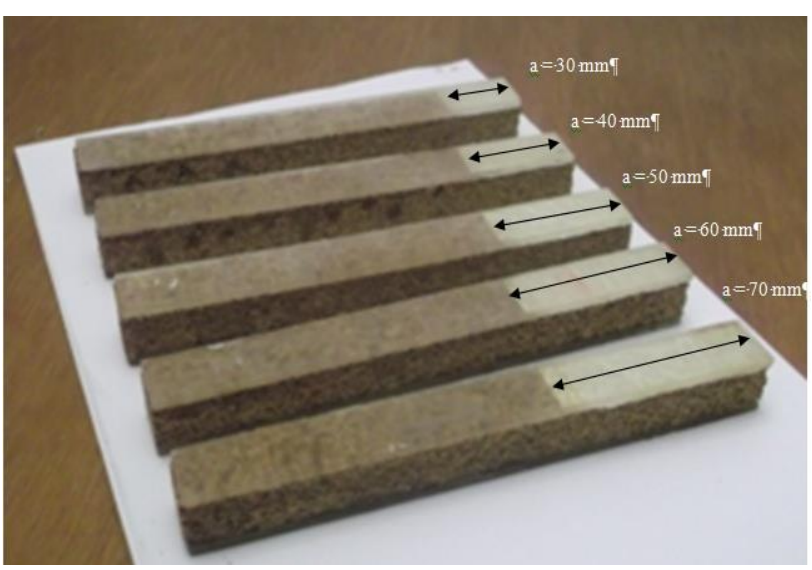

Figure 5. DCB specimens differentiated by the initial crack

To connect specimens with jaws of machine, we realized a device allowing the free rotation of specimens during the test to avoid additional efforts. This device consists of two connecting pieces, two hinges and two pins. See Figure 6. The connection between the test machine and the specimen is made by two connecting pieces which connect with two hinges with two pins. These two connecting pieces are glued in the end of lips of DCB specimen (Figure 7-a).

To study the behavior of the material with respect to delamination, we prepared five samples of the sandwich material in order to carry out the tests in the machine presented above. The position of the DCB specimen on the test machine is perpendicular to axis of jaws of this machine (Figure 7-b). These tests were conducted on "INSTRON" universal machine type 5969, with computer-controlled acquisition Bluehill3, with $50 \mathrm{KN}$ force sensors and $1[\mathrm{~mm} / \mathrm{min}]$ constant crosshead speed (Figure 7-c).

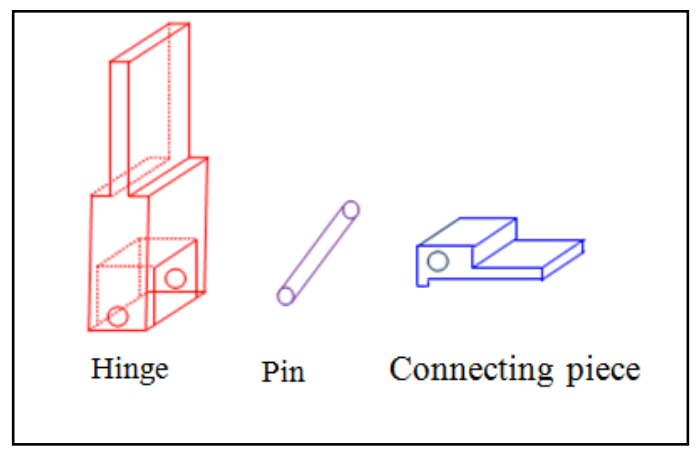

Figure 6. Connecting device

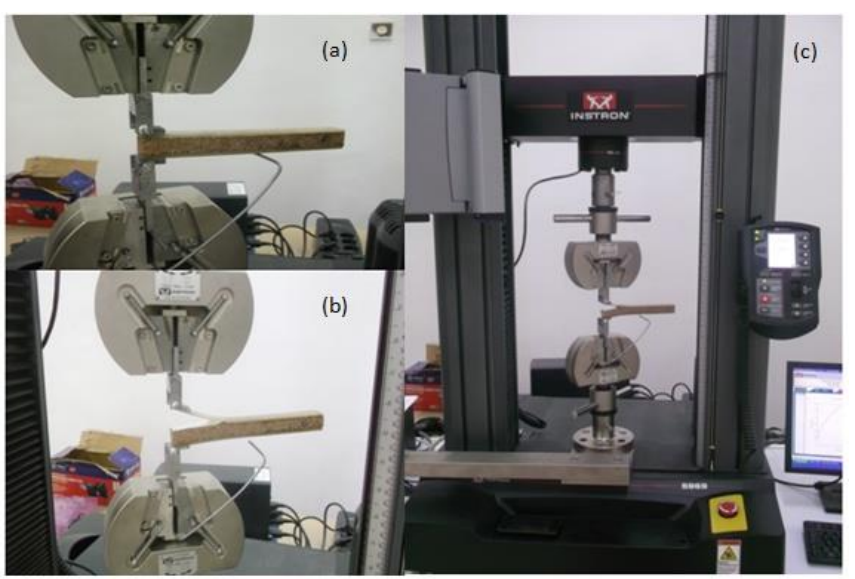

Figure 7. DCB specimen on the test machine

\section{RESULTS}

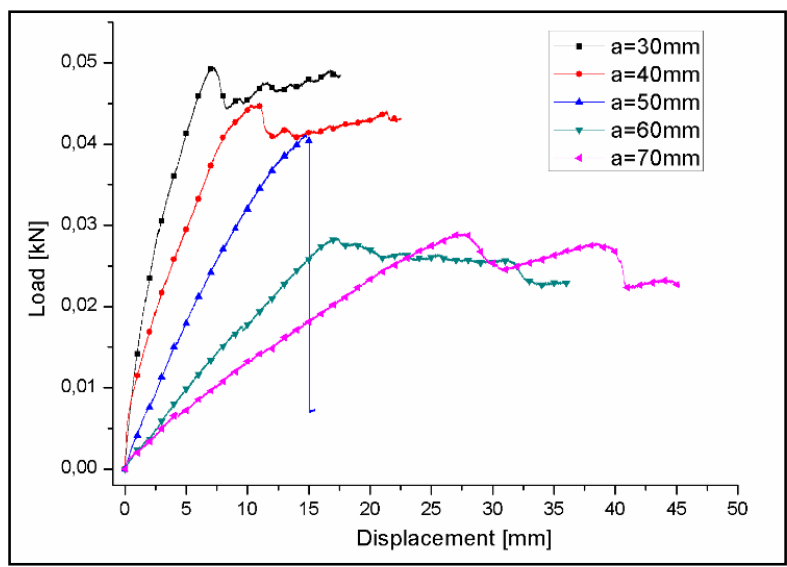

Figure 8. $\operatorname{Load}(\mathrm{N})$-Displacement $(\delta)$ in delamination tests of DCB specimens differenced by initial crack

Figure 8 presents a typical load-displacement curve for the delamination tests. The DCB specimens are differentiated by initial crack lengths $(a=30,40,50,60$ and $70 \mathrm{~mm})$. Analysis of these curves shows three distinct parts differenced by a change in the shape of the curve. The occurred crack propagation is in an unstable manner throughout the test. The 
load increases linearly prior to crack initiation in the first part and then of non-linear behavior in the second part up to the maximum value of load. The beginning of this part corresponds to the macroscopic initiation crack. Then a load is decreased in the beginning of last part.

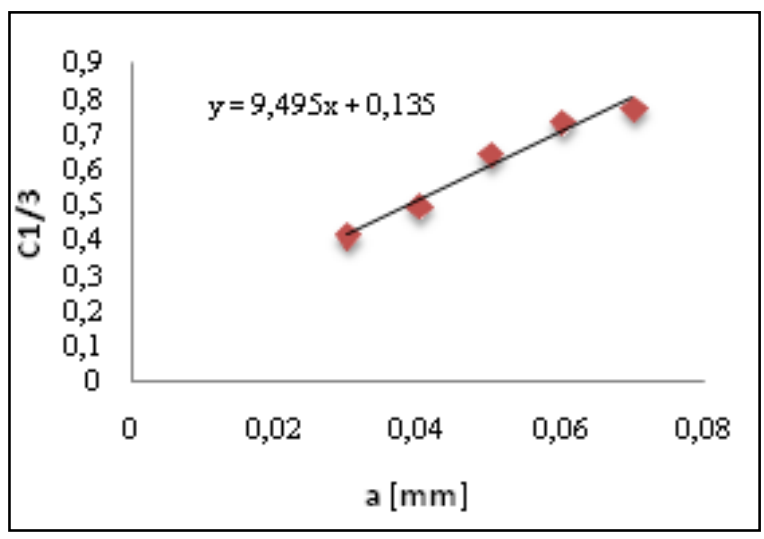

Figure 9. Determination of $|\Delta|$ parameter by the graph

$$
\mathrm{C}^{1 / 3}=\mathrm{f}(\mathrm{a})
$$

Figure 9 presents the graph $\mathrm{C}^{1 / 3}=\mathrm{f}$ (a) to determine the parameter $|\Delta|$. This parameter permits the calculation of the energy release rate $\left(\mathbf{G}_{\mathbf{I C}}\right)$ by Eq. (4). Table 3 presents the average values of $\left(\mathbf{G}_{\mathbf{I C}}\right)$ in sandwich of our study (cork agglomerate/Glass fiber-Polyester). We conclude that energy release Rate at initiation of a crack in specimens remains almost constant despite the variation of the initial crack. Therefore, toughness presented by the rate of energy release is considered to be intrinsic of material.

By comparing the value of the toughness of the present material which is $63545 \mathrm{~J} / \mathrm{m}^{2}$ with another sandwich material from the literature (plywood as skin and polystyrene as core) which is equal to $22411 \mathrm{~J} / \mathrm{m}^{2}$ [17], we can say that this material shows a real improvement in mechanical characteristics.

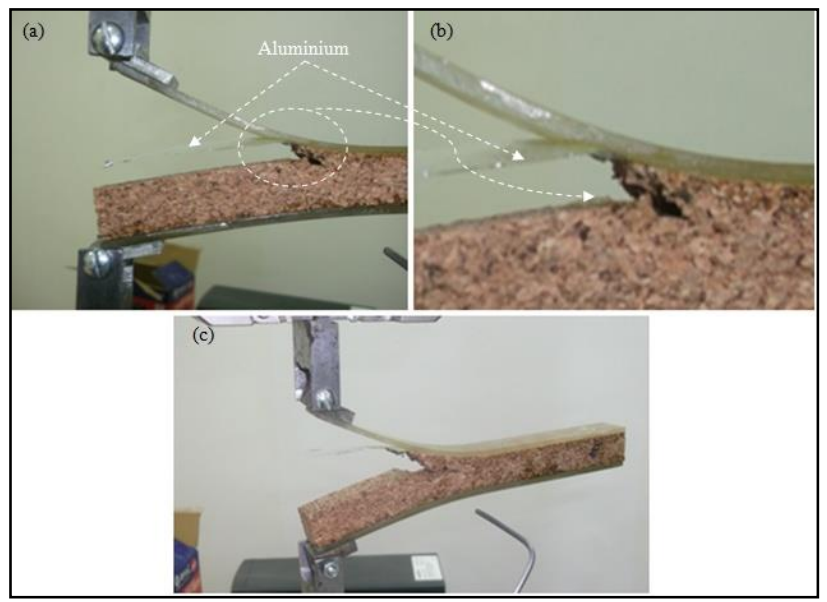

(a) Opening initial crack, (b) Magnification of Opening initial crack, (c) crack propagate

Figure 10. Macroscopic observation in delamination test at DCB specimen

Figure 10 shows the opening of the crack in the delamination test of the sandwiches which starts with micro cracking of the adhesive. It is located between the upper skin and the core $(a, b)$. These micro cracks develop to a critical state where the opening of the crack propagates inside the core which causes the fall of the load $c$.

The propagation of the crack inside the core after the fall of the load shows a good adhesion (skins - core).

Table 3. Average values of energy release rate $\left(\mathrm{G}_{\mathrm{IC}}\right)$

\begin{tabular}{ccccc}
\hline $\mathbf{a}[\mathbf{m m}]$ & $\mathbf{P}[\mathbf{N}]$ & $\boldsymbol{\delta}[\mathbf{m m}]$ & $\mathbf{C}[\mathbf{m m} / \mathbf{N}]$ & $\mathbf{G I C}\left[\mathbf{J} / \mathbf{m}^{2}\right]$ \\
\hline 30 & 23.03 & 1.6233 & 0.0705 & 63436.968 \\
\hline 40 & 18.32 & 2.2299 & 0.1217 & 56530.213 \\
\hline 50 & 14.53 & 3.8188 & 0.2628 & 64821.962 \\
\hline 60 & 13.12 & 5.1200 & 0.3902 & 67898.652 \\
\hline 70 & 12.64 & 5.7767 & 0.4570 & 65038.992 \\
\hline & & & GIC (average) & 63545.357 \\
$|\boldsymbol{\Delta}|$ & $\mathbf{b}[\mathbf{m m}]$ & & Standard deviation & 4243.6964 \\
0.0142 & 0.02 & & CV [\%] & 6.67 \\
\hline
\end{tabular}

\section{CONCLUSIONS}

The main objective of this investigation is to study the damage by delamination of sandwiches composite materials. This damage mode of sandwich structures, can be particularly detrimental for structural behavior. Core cracking and face/core separation are common failure modes in cork agglomerate cored sandwich structures. These tested sandwiches samples are made of cork agglomerate as core, sandwiched between glass fiber-polyester (laminate of 04 layers) as skins. The experimental study consisted of elaborate different types of sandwiches samples to determine their break in mode I. Double cantilever beams (DCB) specimen are differentiated by the size of the initial crack. This latter is obtained by placing during the elaboration, an aluminum film between the core and the upper skin with different initial crack lengths $(a=30,40,50,60$ and $70 \mathrm{~mm})$. The initiation of crack in the (DCB) specimens is characterized by the toughness, which is expressed by the rate of energy release $\left(\mathrm{G}_{\mathrm{IC}}\right)$, which is determined by the modified beam theory (MBT), while the skins are considered as isotropic material and the core is considered orthotropic.

Through the experimental study, the following conclusions can be drawn:

Energy release Rate at initiation of a crack specimens remains almost constant despite the variation of the initial crack. Therefore, the rate of energy release is considered to be intrinsic to the material.

The delamination test shows a good adhesion (skins - core).

In comparison between the tenacity of the present material and other sandwich material from the literature (plywood), we can say that this material shows a real improvement in mechanical characteristics. Nevertheless, a further study of moisture absorption appears to be necessary. Especially for 
uses in thermal insulation in cold rooms or drying foodstuffs, as it can cause the formation of bacteria and parasites.

Finally, we intend to enhance this work by future studies on the thermal characterization of different composite materials for thermal insulation applications, especially in solar air flat plate collectors and drying chambers.

\section{REFERENCES}

[1] Rocca, S.V., Nanni, A. (2005). Mechanical characterization of sandwich structure comprised of glass fiber reinforced core: Part 1. $3^{\text {rd }}$ International Conference of Composites in Construction, Lyon, France.

[2] Krishanu, G., Prasun, C., Chiranjit, B. (2020). Study of modal behavior of sandwich structure with various core materials an analytical approach. Revue des Composites et des Matériaux Avancés-Journal of Composite and Advanced $\quad$ Materials, 30(1): 15-21. https://doi.org/10.18280/rcma.300103

[3] Shahdin, A., Mezeix, L., Bouvet, C.H., Morlier, J., Yves, G. (2009). Fabrication and mechanical testing of glass fiber entangled sandwich beams: A comparison with honeycomb and foam sandwich beams. Composite Structures, 90(4): 404-412. https://doi.org/10.1016/j.compstruct.2009.04.003

[4] Hayman, B., Berggreen, C., Jenstrup, C., Karlsen, K. (2008). Advanced mechanical testing of sandwich Materials. Eighth International Conference on Sandwich Structures (ICSS 8), pp. 417-427. https://orbit.dtu.dk/en/publications/advancedmechanical-testing-of-sandwich-materials.

[5] Carlsson, L.A., Sendlein, L.S., Merry, S.L. (1991). Characterization of face sheet/core shear fracture of composite sandwich beams. Journal of Composite Materials, 25(1): 101-116. https://doi.org/10.1177/002199839102500105

[6] Frostig, Y., Baruch, M. (1990). Bending of sandwich beams with transversely flexible core. AIAA Journal, 28(3): 523-531. https://doi.org/10.2514/3.10423

[7] Djemai, H., Hecini, M., Labed, A. (2016). On the characterization of sandwich panels for solar flat plate collectors' applications: Theoretical and experimental investigation. Journal of Applied Engineering Science \& Technology, 2(1): 15-22.

[8] Julien, B., François, X.H., Nathalie, G., Pascal, R. (2014). Suivi par émission acoustique de structure sandwich composite/nid d'abeille lors de sollicitation en flexion 3 points. Analyse de la dynamique des précurseurs de la rupture. Revue des Composites et des Matériaux Avancés-Journal of Composite and Advanced Materials, 24(4): 393-402. https://doi.org/10.3166/rcma.24.393402

[9] Carlsson, L.A., Matteson, R.C., Aviles, F., Loup, D.C. (2005). Crack path in foam cored DCB sandwich fracture specimens. Composites Science and Technology, 65(15-
16):

$2612-2621$

https://doi.org/10.1016/j.compscitech.2005.05.013

[10] Gordnian, K.H.H.M.P., Hadavinia, H., Mason, P.J., Madenci, E. (2008). Determination of fracture energy and tensile cohesive strength in Mode I delamination of angle-ply laminated composites. Composite Structures, 82(4): https://doi.org/10.1016/j.compstruct.2007.02.008

[11] Bourennane, H., Gueribiz, D., Benchatti, A. (2018). Mechanical behavior modeling of damaged composite matrix. Revue des Composites et des Matériaux Avancés, 28(3): 383-393. https://doi.org/10.3166/RCMA.28.383393

[12] Touam, L., Derfouf, S. (2021). Effect of the varying percentage diss fiber on mechanical behaviour of the based polyester bio-composite. Revue des Composites et des Matériaux Avancés-Journal of Composite and Advanced Materials, 31(3): 175-180. https://doi.org/10.18280/rcma.310309

[13] Guellai, F., Labed, A., Moummi, N., Mahboub, C. (2019). Measurement and analysis of thermal-hydraulic performance of curved and plate flat solar air heaters; a comparative study. Instrumentation Mésure Métrologie, 18(6): 553-558. https://doi.org/10.18280/i2m.180606

[14] Avilés, F., Carlsson, L.A. (2008). Analysis of the sandwich DCB specimen for debond characterization. Engineering Fracture Mechanics, 75(2): 153-168. https://doi.org/10.1016/j.engfracmech.2007.03.045

[15] Khoshravan, M., Mehrabadi, F.A. (2012). Fracture analysis in adhesive composite material/aluminum joints under mode-I loading; experimental and numerical approaches. International Journal of Adhesion and Adhesives, 39 : 8-14. https://doi.org/10.1016/j.ijadhadh.2012.06.005

[16] Lakreb, N., Bezzazi, B., Pereira, H. (2015). Mechanical behavior of multilayered sandwich panels of wood veneer and a core of cork agglomerates. Materials \& Design (1980-2015), 65: 627-636. https://doi.org/10.1016/j.matdes.2014.09.059

[17] Djemai, H. (2017). Contribution to the study of damage in sandwich composite materials. PHD thesis in Mechanical Engineering, University of Biskra (Algeria).

\section{NOMENCLATURE}

specimen width, $\mathrm{mm}$

a crack length, $\mathrm{mm}$

C Compliance, $\mathrm{mm} / \mathrm{N}$

GIC energie realise rate, $\mathrm{J} / \mathrm{m}^{2}$

\section{Greek symbols}

magnitue of the intercept of $\mathrm{C}=\mathrm{f}(\mathrm{a})$ with the (a)-axis 